\title{
Polymerization of Monomers with Methyl Chlorosulfite and Hydroperoxide at Subzero Temperatures
}

\author{
Hiroshi Minato* and Hiroyuki OHta \\ Department of Chemistry, International Christian University, \\ Fukasawa, Setagaya-ku, Tokyo, Japan.
}

(Received February 22, 1973)

\begin{abstract}
At $-24^{\circ} \mathrm{C}$, a mixture of methyl chlorosulfite and a hydroperoxide efficiently initiated polymerization of methyl methacrylate, vinyl acetate, vinyl chloride, and styrene. The rate of polymerization of vinyl chloride was proportional to $(t$ $\mathrm{BuOOH})^{0.58}\left(\mathrm{ClSO}_{2} \mathrm{Me}\right)^{0.67}\left(\mathrm{CH}_{2}=\mathrm{CHCl}\right)^{1.2}$. A mixture of $\mathrm{ROONa}$ and $\mathrm{ClSO}_{2} \mathrm{Me}$ was equally effective. A plausible scheme for generation of free radicals is presented, which involves ROOSOMe as the very unstable intermediate.

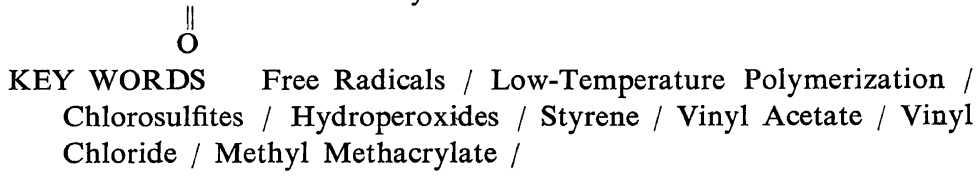

Thermal decompositions of various peroxides and azo compounds yield free radicals, but usually at temperatures much higher than room temperature. Free radicals can be generated at temperatures lower than room temperature when one uses an inorganic redox pair. However, when organic vinyl monomers are polymerized by use of a redox pair, the system is necessarily heterogeneous, that is, either in the state of suspension or emulsion.

It has been found in our laboratories that a mixture of thionyl chloride, methanol, and $t$ butyl hydroperoxide generated free radicals near $-20^{\circ} \mathrm{C}$ and initiated efficiently the polymerization of vinyl chloride. ${ }^{1}$ In order to clarify the chemistry of this initiating system, a detailed investigation has been carried out, and the results are described in this paper.

\section{EXPERIMENTAL}

\section{Materials}

Cumyl hydroperoxide was converted to its sodium salt by treatment with a concentrated $\mathrm{NaOH}$ solution, and the salt was washed with petroleum ether and dried. Methyl chlorosulfite was prepared by the method of Berti, ${ }^{2}$ bp $30^{\circ} \mathrm{C}$

\footnotetext{
* Present Address: Department of Chemistry, Tokyo Metropolitan Univ., Setagaya, Tokyo 158.
}

(27 $\mathrm{mm})$. Vinyl chloride was purified by passing it through an aqueous $\mathrm{AgNO}_{3}$ solution and anhydrous $\mathrm{CaCl}_{2}$. Methyl methacrylate was distilled at $35-36^{\circ} \mathrm{C}(23 \mathrm{~mm})$. 1,1-Diphenylethylene was distilled at $140-142^{\circ} \mathrm{C}(17 \mathrm{~mm})$. Dichloromethane was shaken with a dilute $\mathrm{Na}_{2} \mathrm{CO}_{3}$ solution, dried over anhydrous $\mathrm{Na}_{2} \mathrm{SO}_{4}$, and distilled at $40.1^{\circ} \mathrm{C}$.

Effects of Changes of the Concentrations of the Initiators and Vinyl Chloride on the Rates of Polymerization

Four $\mathrm{m} l$ of methanol, $4 \mathrm{~m} l$ of vinyl chloride, $3.0 \mathrm{~mol} \%$ of $t$-butyl hydroperoxide (mole per 100 mole of a monomer), and 2.0,3.0,6.0, or $8.0 \mathrm{~mol} \%$ of methyl chlorosulfite were mixed at $-24^{\circ} \mathrm{C}$, and the initial rate of polymerization was determined. The rates were found to be proportional to $\left[\mathrm{ClSO}_{2} \mathrm{Me}\right]^{0.67}$.

Four $\mathrm{m} l$ of methanol, $4 \mathrm{~m} l$ of vinyl chloride, $3.0 \mathrm{~mol} \%$ of methyl chlorosulfite, and 2.0, 3.0, 4.0 , or $6.0 \mathrm{~mol} \%$ of $t$-butyl hydroperoxide were mixed at $-24^{\circ} \mathrm{C}$, and the initial rate of polymerization was determined. The rates were found to be proportional to $[t-\mathrm{BuOOH}]^{0.58}$.

Then $2.0,3.0,4.0$, or $5.0 \mathrm{ml}$ of methanol, $6.0,5.0,4.0$, or $3.0 \mathrm{~m} l$ of vinyl chloride, 3.0 mol\% of methyl chlorosulfite, and $3.0 \mathrm{~mol} \%$ of $t$-butyl hydroperoxide were mixed at $-24^{\circ} \mathrm{C}$, 
and the initial rate of polymerization was determined. The rates were found to be proportional to [vinyl chloride] ${ }^{1.2}$.

\section{Determination of the Sulfur Contents in the PVC Produced}

A mixture of $25.0 \mathrm{~m} l$ of methanol, $25.0 \mathrm{~m} l$ of vinyl chloride, 3 mol $\%$ of $t$-butyl hydroperoxide, and $3.0 \mathrm{~mol} \%$ of methyl chlorosulfite was allowed to react at $-24^{\circ} \mathrm{C}$ for two days. The polymer obtained $(23.5 \mathrm{~g})$ was dissolved in THF, and precipitated by the addition of methanol. This dissolution-precipitation was repeated twice more. The average molecular weight of the polymer was determined by measurements of the viscosity of its cyclohexanone solutions: $M=3.14 \times 10^{5}$.

A sample of the PVC obtained $(10.94 \mathrm{~g})$ was heated with sodium, and the sulfur contained in the polymer was converted to sodium sulfide, which was oxidized by nitric acid to sulfate. Addition of barium chloride yielded a precipitate of barium sulfate. The weight of the barium sulfate obtained $(0.0565 \mathrm{~g})$ indicated that the PVC contained $0.071-\%$ sulfur. This figure shows that a PVC molecule contains $7 \mathrm{~S}$ atoms on the average.

Reaction between Methyl Chlorosulfite and Sodium Salt of Cumyl Hydroperoxide in Dichloromethane.

A dichloromethane solution $(50 \mathrm{ml})$ of methyl chlorosulfite $(8.06 \mathrm{~g}, 72 \mathrm{mmoles})$ was stirred into dichloromethane $(150 \mathrm{ml})$ containing solid sodium salt of cumyl hydroperoxide $(12.09 \mathrm{~g}, 66$ mmole) in a three-necked flask in $20 \mathrm{~min}$ at $-23^{\circ} \mathrm{C}$ under a nitrogen atmosphere. Then the mixture was gradually warmed up to $30^{\circ} \mathrm{C}$ and kept there for 2 days. Then the products in the mixture were analyzed by fractional distillation, gas chromatography, and infrared spectroscopy.

\section{Polymerization of Monomers by $\mathrm{ClSO}_{2} \mathrm{Me}-\mathrm{ROOH}$ in Methanol}

To a mixture of $5 \mathrm{~m} l$ of a monomer, $5 \mathrm{~m} l$ of methanol, and a certain amount of a hydroperoxide at $-24^{\circ} \mathrm{C}$, methyl chlorosulfite was added. The monomer solution was allowed to polymerize at $-24^{\circ} \mathrm{C}$ or at a higher temperature. The yield of polymer was determined, and its viscosity-average molecular weight was deter- mined.

Reaction among Methyl Chlorosulfite, Sodium Salt of Cumyl Hydroperoxide, and 1,1-Diphenylethylene in Dichloromethane

After a dichloromethane solution $(20 \mathrm{ml})$ of 1,1-diphenylethylene $(13.03 \mathrm{~g}, 77 \mathrm{mmole})$ containing sodium salt of cumyl hydroperoxide ( $1.75 \mathrm{~g}, 10 \mathrm{mmole})$ was deaerated by bubbling nitrogen, a dichloromethane solution $(5 \mathrm{ml})$ of methyl chlorosulfite $(1.18 \mathrm{~g}, 10 \mathrm{mmole})$ was added drop by drop at $-23^{\circ} \mathrm{C}$ under a nitrogen atmosphere. Then the mixture was gradually warmed up to $30^{\circ} \mathrm{C}$ and kept there for 2 days. The mixture was filtered, and the filtrate was distilled under reduced pressure. The highboiling residue was subjected to column chromatography on alumina. The first substance eluted with petroleum ether was unchanged 1,1-diphenylethylene, and the second substance eluted was a white crystalline substance $(3.60 \mathrm{~g})$ of $\mathrm{mp}$ $99^{\circ} \mathrm{C}$. The third substance eluted was found to be benzophenone $(0.298 \mathrm{~g})$ on the bases of its melting point $\left(46.5-48^{\circ} \mathrm{C}\right)$ and infrared spectrum. The main product melting at $99^{\circ} \mathrm{C}$ was identified as 1,1,3,3-tetraphenylcyclobutane (the head-totail dimer of 1,1-diphenylethylene) by the following method. Though its melting point was lower than those reported in the literature $\left(201^{\circ} \mathrm{C}^{3}\right.$ and $\left.141^{\circ} \mathrm{C}^{4}\right)$, its identity seems unquestionable because of its NMR spectrum $(4 \mathrm{H}$ singlet at $\delta 1.40 \mathrm{ppm}$ and $20 \mathrm{H}$ at $\delta \quad 6.8-7.1$ ppm), mass spectrum $(360,283,256,207,195$, 180, 166, etc.), and $\mathrm{CH}$ analysis (found: $\mathrm{C}$, 92.79, H, 6.74\%; calcd for $\mathrm{C}_{28} \mathrm{H}_{24} ; \mathrm{C}, 93.40$, $\mathrm{H}, 6.66 \%)$.

\section{RESULTS AND DISCUSSION}

Styrene, vinyl acetate, methyl methacrylate, and vinyl chloride were polymerized in methanol by $\mathrm{Me}_{3} \mathrm{COOH}-\mathrm{ClSO}_{2} \mathrm{Me}$ at $-24^{\circ} \mathrm{C}$ or near $0^{\circ} \mathrm{C}$. The results summarized in Table $\mathrm{I}$ show that MMA, vinyl chloride, and vinyl acetate polymerize very well even at $-24^{\circ} \mathrm{C}$ by this initiator, whereas polymerization of styrene proceeds rather slowly.

In order to determine the effects of changes of the concentrations of the initiators and vinyl chloride on the rate of polymerization, initial 
Polymerization of Monomers with Methyl Chlorosulfite and Hydroperoxide at Subzero Temperatures

Table I. Polymerization of monomers by $\mathrm{Me}_{3} \mathrm{COOH}-\mathrm{ClSO}_{2} \mathrm{Me}$ system ${ }^{\mathrm{a}}$

\begin{tabular}{|c|c|c|c|c|c|c|c|}
\hline \multicolumn{2}{|c|}{ Monomer } & \multirow{2}{*}{$\begin{array}{c}\mathrm{ClSO}_{2} \mathrm{Me} \\
1.27 \mathrm{mmol}\end{array}$} & \multirow{2}{*}{$\begin{array}{r}\mathrm{Me}_{3} \mathrm{COOH} \\
1.27 \mathrm{mmol}\end{array}$} & \multirow{2}{*}{$\frac{{ }^{\circ} \mathrm{C}}{\text { Temp, }}$} & \multirow{2}{*}{$\frac{\mathrm{Time}_{\mathrm{hr}}}{6.1}$} & \multirow{2}{*}{$\begin{array}{l}\text { Polymer } \\
\text { yield, \% } \\
2.8\end{array}$} & \multirow{2}{*}{$\begin{array}{l}\text { Viscosity-average } \\
\text { molecular weigh }\end{array}$} \\
\hline Styrene & $45.0 \mathrm{mmol}$ & & & & & & \\
\hline Styrene & $45.0 \mathrm{mmol}$ & $1.27 \mathrm{mmol}$ & $1.27 \mathrm{mmol}$ & +2.0 & 18.5 & 6.0 & 4500 \\
\hline VAc & $54.0 \mathrm{mmol}$ & $1.61 \mathrm{mmol}$ & $1.61 \mathrm{mmol}$ & -24.0 & 6.0 & 48.8 & 7750 \\
\hline VAc & $54.0 \mathrm{mmol}$ & $1.61 \mathrm{mmol}$ & $1.61 \mathrm{mmol}$ & -2.0 & 5.5 & 50.2 & 7560 \\
\hline MMA & $35.0 \mathrm{mmol}$ & $1.05 \mathrm{mmol}$ & $1.05 \mathrm{mmol}$ & -24.0 & 21 & 92.4 & 60200 \\
\hline MMA & $47.0 \mathrm{mmol}$ & $1.41 \mathrm{mmol}$ & $1.41 \mathrm{mmol}$ & -4.0 & 20 & 93.5 & $\mathrm{~b}$ \\
\hline $\mathrm{VCl}$ & $78.0 \mathrm{mmol}$ & $2.34 \mathrm{mmol}$ & $2.34 \mathrm{mmol}$ & -24.0 & 23 & 81.5 & 63700 \\
\hline
\end{tabular}

a $5 \mathrm{~m} l$ of a monomer, $5 \mathrm{ml}$ of methanol, and the initiator pair were mixed.

b Not determined.

Table II. Polymerization of monomers by $\mathrm{PhMe}_{2} \mathrm{COONa}_{-} \mathrm{ClSO}_{2} \mathrm{Me}$ system ${ }^{\mathrm{a}}$

\begin{tabular}{cccccc}
\hline Monomer & $\mathrm{ClSO}_{2} \mathrm{Me}$ & $\mathrm{PhMe}_{2} \mathrm{COONa}$ & $\mathrm{Temp},{ }^{\circ} \mathrm{C}$ & $\mathrm{Time}, \mathrm{hr}$ & Polymer yield, $\%$ \\
\hline MMA $100 \mathrm{mmol}$ & $5.00 \mathrm{mmol}$ & $5.00 \mathrm{mmol}$ & +20.0 & 48 & 0 \\
MMA $100 \mathrm{mmol}$ & $5.00 \mathrm{mmol}$ & $5.00 \mathrm{mmol}$ & -23.0 & 48 & 100 \\
VCl $100 \mathrm{mmol}$ & $5.00 \mathrm{mmol}$ & $5.00 \mathrm{mmol}$ & -23.0 & 48 & 75 \\
\hline
\end{tabular}

a The initiators were added to a mixture of equal volumes of a monomer and methanol.

rates of polymerization were measured with varied concentrations of the initiators and vinyl shloride at $-24^{\circ} \mathrm{C}$. It was found that the rate of polymerization is expressed by the following equation.

$R_{p}=k\left(\mathrm{Me}_{3} \mathrm{COOH}\right)^{0.58}\left(\mathrm{ClSO}_{2} \mathrm{Me}\right)^{0.67}\left(\mathrm{CH}_{2}=\mathrm{CHCl}\right)^{1.2}$

In order to investigate the mechanism of initiation further, the identification of the prolucts of the reaction between $\mathrm{ROOH}$ and methyl chlorosulfite was attempted. For this purpose cumyl hydroperoxide was used in place of $t$-butyl hydroperoxide. However, when the ceaction between cumyl hydroperoxide and nethyl chlorosulfite was investigated, considertble amounts of phenol and acetone were found. These products are ascribable to the heterolytic lecomposition of cumyl hydroperoxide, catalyzed sy the hydrogen chloride formed by the reacion between the hydroperoxide and methyl :hlorosulfite. Therefore, the sodium salt of the lydroperoxide was used instead of the hydroseroxide itself.

In order to check that the $\mathrm{ROONa}-\mathrm{ClSO}_{2} \mathrm{Me}$ iystem is equally capable of initiating polymerzation, vinyl chloride and MMA were polynerized; the results are summarized in Table II. $t$ is clearly shown that this system initiates polymerization efficiently at low temperatures. The fact that no polymer was formed at $+20^{\circ} \mathrm{C}$ indicates that the $\mathrm{PhMe}_{2} \mathrm{COONa}-\mathrm{ClSO}_{2} \mathrm{Me}$ system was an effective initiator only at very low temperature but was used up rapidly at such a high temperature. In contrast, the $\mathrm{Me}_{3} \mathrm{COOH}-$ $\mathrm{ClSO}_{2} \mathrm{Me}$ system was an effective initiator even at $-2--4^{\circ} \mathrm{C}$, as shown in Table I. Thus, the $\mathrm{ROOH}-\mathrm{ClSO}_{2} \mathrm{Me}$ pair can be used as initiators both at $-24^{\circ} \mathrm{C}$ and $-2^{\circ} \mathrm{C}$, whereas the ROONa$\mathrm{ClSO}_{2} \mathrm{Me}$ pair is effective only at lower temperatures near $-20^{\circ} \mathrm{C}$. These findings can be explained by assuming that ROOSOMe is formed O

as the intermediate. Since the nucleophilic attack of $\operatorname{ROO} \ominus$ on the sulfinyl sulfur atom of $\mathrm{ClSO}_{2} \mathrm{Me}$ is much faster than that of $\mathrm{ROOH}$, the $\mathrm{ROONa}-\mathrm{ClSO}_{2} \mathrm{Me}$ pair forms ROOSOMe Ö

very rapidly and the peroxysulfite produced decomposes rapidly, whereas the $\mathrm{ROOH}-\mathrm{ClSO}_{2} \mathrm{Me}$ pair forms the peroxysulfite very slowly and free radicals are produced slowly and steadily from the peroxysulfite formed.

When the sulfur content of the PVC molecules produced was determined, it was found that $7 \mathrm{~S}$ atoms were present per one PVC mole- 
cule on the average. If $\mathrm{Me}_{3} \mathrm{CO}$ and. $\mathrm{OSOMe}$ OI are the radicals initiating the polymerization, this figure is greater than what is expected. This greater sulfur content is probably ascribable to one of the following two routes: a) incorporation of sulfur dioxide (produced by the decomposition of the initiators) by free-radical copolymerization or b) hydrogen abstraction from the PVC chains and the combination of such polymer radicals with .OSOMe.

\section{O}

Then, in order to determine the products of the decomposition of the initiator, the reaction between methyl chlorosulfite and sodium salt of cumyl hydroperoxide in the absence of mono- mers was investigated. From the reaction mixture, the following products were identified; $\mathrm{PhMe}_{2} \mathrm{COH}, 31 ; \mathrm{PhCOMe}, 2.2 ; \mathrm{Me}_{2} \mathrm{CO}, 8.7$; $(\mathrm{MeO})_{2} \mathrm{SO}, 10.4 ; \quad \mathrm{SO}_{2}$ gas, $6.7 \mathrm{~mol} / 100 \mathrm{~mol}$ $\mathrm{PhMe}_{2} \mathrm{COONa}$. These results can be rationalized in terms of the formation of cumyloxy radical, $\mathrm{PhMe}_{2} \mathrm{CO}$.

In order to trap the free radicals formed, the sodium salt of cumyl hydroperoxide and methyl chlorosulfite were allowed to react in dichloromethane in the presence of 1,1-diphenylethylene. However, the main hydrocarbon product isolated was 1,1,3,3-tetraphenylcyclobutane, which did not contain fragments of the initiators. Apparently the following reaction took place.

$$
\begin{aligned}
& \mathrm{R} \cdot+\mathrm{CH}_{2}=\mathrm{CPh}_{2} \longrightarrow \mathrm{R}-\mathrm{CH}_{2}-\dot{\mathrm{C}} \mathrm{Ph}_{2} \\
& \mathrm{R}-\mathrm{CH}_{2}-\dot{\mathrm{C}} \mathrm{Ph}_{2}+\mathrm{CH}_{2}=\mathrm{CPh}_{2} \longrightarrow \mathrm{R}-\mathrm{CH}_{2}-\mathrm{CPh}_{2}-\mathrm{CH}_{2}-\dot{\mathrm{C}} \mathrm{Ph}_{2} \\
& \mathrm{R}-\mathrm{CH}_{2}-\mathrm{CPh}_{2}-\mathrm{CH}_{2}-\dot{\mathrm{CPh}} \longrightarrow \mathrm{Ph}_{2} \longrightarrow \underset{\mathrm{C}}{\mathrm{C}}-\mathrm{CPh}_{2} \\
& \mathrm{Ph}_{2} \mathrm{C}-{ }_{\mathrm{C}}+\mathrm{R}
\end{aligned}
$$

A plausible scheme for generation of free radicals in this system is shown below.

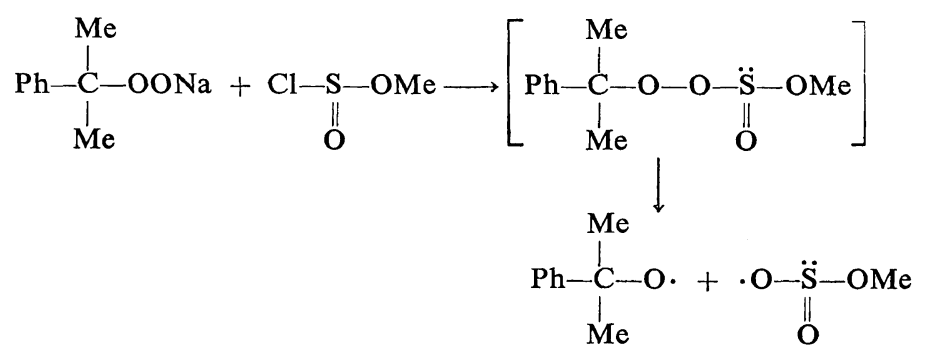

If the intermediate in this reaction is the peroxysulfite shown above, it is one of the least stable peroxides known, and its ease of decomposition is comparable to that of ethyl $t$-butylperoxy azodicarboxylate $\left(\mathrm{EtO}_{2} \mathrm{C}-\mathrm{N}=\mathrm{N}-\mathrm{CO}_{3} \mathrm{Bu}-t\right) .{ }^{5} \quad t$ Butylperoxy $p$-toluenesulfonate decomposes at room temperature, but yields no free radicals. ${ }^{6}$ Benzoyl $p$-toluenesulfonyl peroxide is fairly stable at room temperature, and yields free radicals at $40-60^{\circ} \mathrm{C}^{7}$ Thus, the peroxysulfite is much less stable than the persulfonates known.

Recently, Flockhart, Ivin, Pink, and Sharma reported that reactions between hydroperoxides and sulfur dioxide yielded free radicals as soon as they were mixed at $20^{\circ} \mathrm{C}$ and the ESR spectra showed that these were $\mathrm{HOSO}_{2}$ and $\mathrm{ROSO}_{2}{ }^{8}$
Although they did not discuss the mechanism of the formation of these radicals from $\mathrm{ROOH}$ and $\mathrm{SO}_{2}$, it is probable that ROÖ̈OH is the O

intermediate, since it may be easily formed by the simple addition of $\mathrm{ROOH}$ to $\mathrm{O}=\mathrm{S}=\mathbf{O}$.

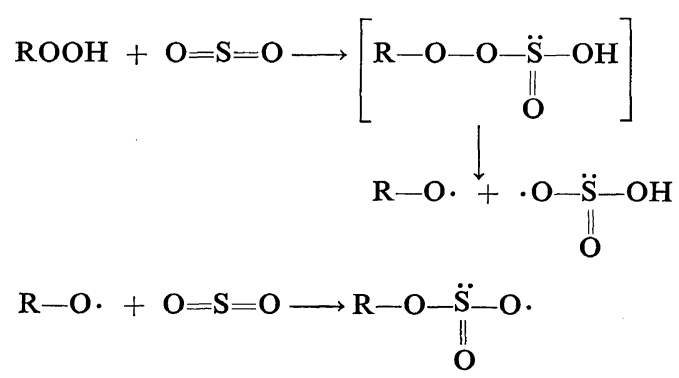
Polymer J., Vol. 5, No. 2, 1973 
Polymerization of Monomers with Methyl Chlorosulfite and Hydroperoxide at Subzero Temperatures

Thus, the findings of Flockhart, et al., and the 2. G. Berti, J. Amer. Chem. Soc., 76, 1213 (1954). results of this investigation suggest that peroxysulfites $\mathrm{R}-\mathrm{O}-\mathrm{O}-\ddot{\mathrm{S}}-\mathrm{OR}^{\prime}\left(\mathrm{R}^{\prime}=\mathrm{H}\right.$ or alkyl $)$ decomO"

pose easily below room temperature, yielding free radicals.

3. B. M. Lebeolev, Zhur. Obshchei Khim., 18, 1696 (1948).

4. R. Riemschneider, J. Amer. Chem. Soc., 78, 844 (1956).

5. H. Minato, Ph. D. Thesis, Harvard University, Cambridge, Mass., 1962.

6. P. D. Bartlett and T. G. Traylor, J. Amer. Chem. Soc., 83, 856 (1961).

REFERENCES

7. R. Hisada, H. Minato, and M. Kobayashi, Bull. Chem. Soc. Japan, 44, 2541 (1971).

1. H. Minato, H. Iwai, K. Hashimoto, and T. Yasui, J. Polym. Sci., Part C, No. 23, 761 (1968).

8. B. D. Flockhart, K. J. Ivin, R. C. Pink, and B. D. Sharma, Chem. Commun., 339 (1971). 